This is an Accepted Manuscript of an article published in Feminist Media Studies on 15 Aug 2019, available online: https://doi.org/10.1080/14680777.2019.1652667

\title{
Feminism in the troll space: Clementine Ford's Fight Like a Girl, social media, and the networked book
}

Clementine Ford's memoir/manifesto hybrid, Fight Like a Girl, was hailed as a significant contribution to feminist debate in Australia when it was published by Allen \& Unwin in 2016. The book is one stage in Ford's considerable media career, developed across traditional journalism, public speaking, and social media. It can be situated in the context of a recent Anglophone publishing trend of similar hybrids between feminist manifesto and memoir (Crispin, 2017; Gay, 2014), as well as - as evidenced by its cover quote from Anne Summers - being part of a much longer history of Australian feminist publishing. This article positions Fight Like a Girl as a networked text, exploring its close and constitutive relationship to Ford's social media presence and its online reception. Both book and reception tap into online feminist conversations and mainstream public debates about feminism in the wake of identity politics, trolling and shaming, and the gendered nature of contemporary online spaces (Jane, 2016; Phillips, 2015). Analysing conversations on Facebook and Twitter and reviews across Goodreads and more traditional media outlets, this article explores the extent to which the book reconfigures, intensifies or enters into existing conversations as it moves through the networked space of post-digital Australian literature.

Keywords: Book publishing; digital feminism; social media; online misogyny; reception studies

\section{Introduction}

Clementine Ford's Fight Like a Girl was hailed as a significant contribution to feminist debate in Australia when it was launched in October 2016. Reviewers described it as 'a fierce and personal call to arms in the campaign for women's rights', (Van Schilt, The Australian, 3 Feb 2017), ‘a snapshot of contemporary feminism' (Brabon, Sydney Morning Herald, 2 Dec 2016) and 'an extended facebook rant' (Anonymous reviewer, Year13, n.d.). Ford's ideas are 'controversial and polarising' (Salvo, The AU Review, 19 Apr 2017), while Ford herself is 'a 
flame-throwing feminist' (Delaney, The Guardian, 28 Sep 2016) and 'a great swearer' (Simic, Sydney Review of Books, 12 Dec 2016). These reviewers' comments reveal the ways in which Ford and Fight Like a Girl were received by the Australian public. First, both persona and book offer an uncompromising and contemporary version of feminism. Secondly, while Ford is operating in public spaces, her work is distinctly personal, in keeping with key fourth-wave trends in the feminist movement, characterised by an embrace of online media and emphasis on transgender issues (Munro, 2013). This personal lens is a key feature of the content of Fight Like a Girl, but the personal is a mediating force-Ford, as public figure, frames the way that the book is read. And thirdly, Ford is a digital native, with the majority of her public work as a feminist conducted via social media, and in particular Facebook.

Fight Like a Girl taps into conversations happening in online feminist communities and mainstream public debates about feminism, building on the significant existing following that Ford has built through social media and journalistic work. With its cover quote from Anne Summers, the book also acts as bridge across a much longer history of Australian feminist publishing. It is placed therefore in two contexts: an historical, Australian one, and a contemporary, international context of debates about feminism in the wake of identity politics (cf. Dean, 1996; Gay, 2014). The book's genesis and reception were built on debates around trolling, and the gendered contestation of contemporary online spaces.

Fight Like a Girl therefore stages itself against an ongoing transformation of public space and possibilities for activism. This is a space where feminism is heavily mediatised, such that the traditional book form that has long served as a platform for feminist activists has to some extent given way to new forms and modes of address in a 'post-digital' environment that privileges self-consciously mediatised modes of voice. This is at the same time an environment that is often extremely hostile to feminism, marked by ideological warfare and 
extreme antagonism, as seen in the emergence of the 'manosphere' of anti-feminist 'men's rights' sites, extreme forms of trolling and flaming, and the routinisation of threats of violence, including rape and death threats. Fight Like a Girl, we argue, represents a complex response to these new conditions of feminist engagement and raises questions about the possibilities of feminist practice in a post-digital media environment defined by culture wars over identity.

\section{Background: The changing face of feminist debate}

Fight Like a Girl was published at a signal moment in feminist history and media history. Public discussions about feminism, as with discussions about issues such as race and immigration and queer politics, have focused increasingly on questions of the possibilities and usefulness of identity politics. At the same time, the media arena in which such debates play out has changed rapidly. In this section we outline three interrelated areas of transformation relevant to understanding Fight Like a Girl as a feminist artefact: changing media ecologies and the mediatisation of feminism, current debates over identity politics and the role of feminism in online culture wars that take place in what, following Whitney Phillips (2015), we call the 'trollspace'.

\section{Feminist media ecologies}

Print culture has long provided an important platform for feminist activism and aesthetics. As Jaime Harker and Cecilia Konchar Farr argue:

Reading was essential in early conceptions of second-wave feminism, as books became a provocation to conversation about readers' own lives and experiences. . . From popular books such as Marilyn French's The Women's Room, Erica Jong's Fear of Flying, Marge Piercy's Small Changes, and Alix Schulman's Memoirs of an Ex-Prom Queen, to smaller feminist press publications such as Audre Lorde's Zami, Rita Mae Brown's Rubyfruit Jungle, 
and Isabel Miller's Patience and Sarah, CR [consciousness-raising] novels provided millions of women with a vicarious "aha" moment that radical CR groups were producing across the United States. (2016, p. 4)

Such books, many of them published by independent feminist presses that sought to challenge any corporate publishing co-option of feminism (Gilley 2016), also provided a brid gehead for the movement of feminist ideas from their originat ing communities into wider debate, where they played a crucial role in redefining the gendered terms of what counts as 'public'. This is notably the case in Australia, where 'second wave' non-fiction books such as Anne Summers' Damned Whores and God's Police (1975), Jan Mercer's edited collection The Other Half (1975), and Miriam Dixson's The Real Matilda (1976) helped set a trajectory in feminist publishing that Fight Like a Girl, with its cover endorsement from Summers, seeks to continue.

Yet this print-centric media ecology, crucial to the advancement of feminist politics, is rapidly changing. While print books continue to play an important role in fomenting cultural change, the term 'post-digital' has been used to describe a media ecology in which print and digital media cultures intermingle (Ludovico 2013, Andersen and Pold 2014, Andersen et al. 2014), and in which established routines of print-based cultural production and mediation are destabilised (Murray and Squires 2013, Murray 2015, Davis 2016, 2017). This is at the same time an environment in which feminism is increasingly mediatised. By this we refer to the process whereby social processes formerly conducted offline are increasingly defined through their relationship with media via four related practices: extending the capacity for the communication of political ideas, substituting previously unmediated practices with mediated practices, amalgamating personal and mass forms of communication, and accommodating social institutions and activities within media logic (Schulz 2004). While such processes have attracted considerable debate (Deacon and Stanyer 2014, 2015, Hepp et al. 2015, Lunt and 
Livingstone 2016), what is clear is the growing role media plays in constituting everyday politics. An element of such mediatisation is arguably the integration of feminism with social media. For example, Alison Dahl Crossley has used the term 'Facebook feminism' to describe emergent practices whereby social media has become central to feminist practices as a forum and organising tool:

Online feminism, or what I call Facebook Feminism, has exploded as a driving force of feminism. . . vivid examples of strong online feminist communities abound, running the gamut from feminist blogs to multinational feminist organizations circulating feminist news. They suggest that Internet activity significantly upheld women's feminist communities. (2017, p. 98)

These post-digital processes of convergence and mediatisation, we argue, are central to the textual dynamics of Fight Like a Girl, which, while offered in book form and while seeking to accrue the cultural capital associated with that form, nevertheless builds on and is made possible by Ford's high social media profile and her presence in other print forms (notably as a magazine columnist), and that also plays out the rhetorical strategies of social media at the level of its text.

\section{From identity politics to intersectionality}

Books by feminists like Summers, Mercer, and Dixson came from a movement that was both collective and individualistic, distilled most famously in the rallying cry of second-wave feminism that 'the personal is political' (cf. Hanisch, 1970), a comment which also had important resonance with civil rights movements and democratic political activism throughout the twentieth century (Heberle, 2015). This phrase and the ideals it espoused are central to the development of the identity politics movement, defined as 'organizing around the specific experience or perspective - or the collective identity, in sociological terms - of a 
given group as well as to organizing that has identity visibility as a goal' (Whittier, 2017:

376). Importantly, identity politics is defined 'in contradistinction to both classic party-based politics and traditional Left politics, which posited only two substantive identities (workers vs. owners or, in today's parlance, the 99 percent vs. the 1 percent)' (Walters, 2018: 476). Identity politics effectively expanded the scope of political action deemed legitimate to encompass personal, domestic, and consciousness-raising activities, but that has also been critiqued as the source of disunity and factionalism between different marginalised groups. This critique came to the fore in the wake of the 2016 US presidential election as an explanation for Hillary Clinton's failure to capture the white working-class vote:

... the fixation on diversity in our schools and in the press has produced a generation of liberals and progressives narcissistically unaware of conditions outside their selfdefined groups, and indifferent to the task of reaching out to Americans in every walk of life. [...] many assume that diversity discourse exhausts political discourse, and have shockingly little to say about such perennial questions as class, war, the economy and the common good. (Lilla, 2016)

The feminist movement (cf. Franke, 2016; Freeman, 2016; Walters, 2018) has responded to these kinds of critique by pointing out that they assume that these kinds of 'identity' categorisations are inhabited only by marginalised groups: the universality they posit is rooted in assumptions of a white, male, cisnormative, heterosexual, and able-bodied default. Lilla's expressed frustration with 'diversity discourse' (2016, our emphasis) illustrates a further point made by contemporary feminists, namely, that these kinds of critiques falsely conflate identity politics with over-zealous political correctness (Goldberg, 2016, cf. also Scott, 1992: 12). 
A further critique of identity politics, derived from late twentieth-century post-structuralism, is that the privileging of identity is limiting in its narrowness and its homogenising tendencies. It is simultaneously a replication of capitalism's fetishation of the private subject, and a flat reduction of diverse subjectivities into over-simplified categories (Diamond, 2012: 64). Yet, identity politics at the same time provides a basis for collective action. As Elin Diamond argues, 'Identity politics is what gets us into the streets to express defiance and solidarity. . . . A politics based on identity requires acts of affiliation and the labour of consciousness-raising to und erstand and enact them' (2012: 64-66).

Despite the problems, both pragmatic and theoretical, that have been raised with identity politics, it continues to structure contemporary feminism. Identity politics is particularly crucial and present in the ethos of intersectionality (Crenshaw, 1989) - the notion that marginalisation and hierarchies of social power are created and reinforced by the interplay between gender, race, class, sexuality, ability, etc. - that has come to shape the digital and twenty-first century fourth-wave feminist movement. A comparable slogan for the fourthwave might be the title of Flavia Dzodan's oft cited and ripped off 2011 essay-cum-blog post 'My Feminism Will Be Intersectional Or It Will Be Bullshit!' (cf. too Dzodan’s 2016 reflections on the circulation of the essay's title as a slogan).

The contemporary relevance of 'the personal' to public conversation might be judged against the booming popularity of personal essays (Bennett, 2015), while post-Trump dismissal of identity politics has been posited as a death sentence for harrowing, first-person narratives (Tolentino, 2017). In print culture, books like Roxane Gay's memoir and bestseller Bad Feminist (2014) and Jessa Crispin's simultaneous dismissal and manifesto Why I Am Not a Feminist (2017) demonstrate a determination to successfully navigate the conflicted status of contemporary feminism, and in particular to successfully navigate the relationship between the individual and the collective. 


\section{Online culture wars}

Feminism at the same time currently operates in a media environment that is increasingly hostile to progressive politics, including identity politics. Ideological battles about these issues have often played out as an intense and ongoing culture war conducted in what we call the 'trollspace'. In using this term we extend on Whitney Phillips work on 'troll spaces' (2015, p. 25) such as 4chan, to refer to the growing array of online spaces, not least the social media feeds of prominent feminists, where interactions are often characterised by highly partisan 'troll wars' (Phillips 2015, p. 24), using highly aggressive language, ridicule and attempts at humiliation that frequently involve threats of physical harm. Definitions of trolling vary enormously, from accounts of malicious attempts to disrupt online forums (Herring et al. 2002; Shaw 2013), to those that characterise it as a mischievous, irreverent practice that frequently calls power to account (Coleman 2012), consistent with theories of political agonism and counterpublics (see Milner 2013a). Trolling can also include vicious behaviours that shade over from agonism into extreme antagonism (Mouffe 2013), and can express not only counterpublic impulses but also anti-public reactionary impulses, intended not merely to question and destabilise democratic norms but to delegitimise and silence its opponents and the very basis on which democratic discourse takes place.

Women and feminism are frequent targets of such discourse: 'popular feminism and its accompanying message of confidence has been met by ... popular misogyny' (Banet-Weiser and Miltner 2016, 172). 'Popular misogyny' routinely seeks to undermine and intimidate women into silence, often through explicit threats of violence, and in general positions women as undeserving of a place in the public sphere, a sentiment expressed by the online epithet commonly aimed at vocal women to go 'back to the kitchen' (Milner 2013b, 81; Jane 2014a). This discourse has been described by Emma Jane as 'e-bile', a term that seeks to name 'the extravagant invective, the sexualized threats of violence, and the recreational 
nastiness that have come to constitute a dominant tenor of Internet discourse' (2014b, 53132), and which frequently includes threats to kill, torture and rape. These attacks on women also include organised trolling and harassment as experienced by women targeted in \#GamerGate (Chess and Shaw 2015), in some cases leading to the physical stalking of women by 'men's rights activists' (Marwick and Caplan 2018). Often in such discourse the internet is itself figured as a male-gendered space that has been improperly colonised by women, as seen by the edict on the bulletin board site 4chan's /b (random) board, which along with its /pol (politically incorrect) board, have been described as the ground zero of online trolling (Phillips 2015) notable for their misogyny (Manivannan 2013), that 'there are no girls on the internet' and demands that women who reveal their gender must show 'tits or GTFO [get the fuck out]' (Milner 2013a, 81). This targeting of women and feminists is in turn linked to notions of 'hegemonic masculinity' that advocate essentialist notions of gender and a return to rigid gender hierarchy, and that associate a 'decline of masculinity' with an all-pervasive 'political correctness' promoted by feminists among other 'social justice warriors' that has stifled those who would otherwise tell the truth about gender relations (Chess and Shaw 2015).

\section{Methods}

We read Fight Like a Girl as a networked object that seeks to negotiate feminism in this new highly mediatised environment. We have an interest simultaneously in the book itself and its relationship to other agents—-people and texts—involved in similar political conversations. Our first line of enquiry is Ford's self-positioning as a public figure through her journalism and online engagement, with a particular interest in the relationship between social media and Ford's writing and self-presentation We then consider the book as a textual object—what it is saying, the style in which it is written, its relationship to other feminist texts, and the ways that social media conversations entered the book itself. We then look at the book's reception, 
in reviews by traditional media outlets, in online reviews on Goodreads, and in conversations in those social media communities.

Our investigation combines methodologies from literary studies-close reading of the source text—with investigation of these digital spaces (cf. Lupton, 2011; Murray, 2018). In examining social media, we used a combination of Twitter Archiving Google Sheets (TAGS), the API-based subscription program Netlytic, and an open-source python scraper taken from GitHub $^{1}$ to create datasets from Twitter and Facebook, the two social media platforms on which Ford has the biggest followings. ${ }^{2}$ We created broad datasets of mentions of Ford on Twitter and of conversations taking place on Ford's public Facebook page to get a sense of how Ford engages with these spaces more generally, covering the four-month period from 22 July 2017-22 November 2017. We also created targeted datasets that home in on the controversy surrounding Ford's promotional event at the Avid Reader bookshop for Fight Like a Girl in June 2017, and the resulting digital attack on Avid Reader from Men's Rights Activist (MRA) groups. Lastly, we collected reviews of Fight Like a Girl from newspaper and book review publications, and from book-centric social media site Goodreads. We conducted close reading of the social media posts and reviews that comprised these datasets, and also tracked patterns of reviewing, rating and commenting over time.

\section{The Public Figure}

Both the production and reception of Fight Like a Girl are framed by Ford's public engagement and public profile. Ford is a weekly columnist for Fairfax-owned Daily Life, a news and lifestyle publication aimed at Australian women. Her contract with major Australian independent Allen \& Unwin to publish Fight Like a Girl was based on a 'raw

\footnotetext{
${ }^{1}$ See https://github.com/PJHRobles/Twitter-Get-Old-Tweets-Scraper

${ }^{2}$ When data collection for the article was finalised (11 May 2018), Ford had 179,007 followers on Facebook and 121,600 followers on Twitter.
} 
proposal' (Ford interview for Pedestrian Daily, 2015), and the book has been seen as a 'natural' extension of her journalistic work (Delaney, 2016). While Ford's journalism may have provided initial leverage and proof-of-concept for her book publishing, her book publishing now authorises her journalistic presence: Daily Life describes her as 'a best-selling author and feminist commentator' (Sydney Morning Herald, n.d.).

At the time of writing, Ford's public-facing Facebook page is followed by 179,007 users, and her Twitter account by $121,600 .{ }^{3}$ Social media are 'stages for self-expression, communication and self-promotion' (van Dijck, 2013: 199), with users performing their identities to a range of different audiences through these sites. This performance is both constrained by and carefully built using the specific interface logics of different sites (van Dijck, 2013: 211). The content of social media profiles, from specific posts and information shared through to the visual composition of profile pictures, are direct personal branding, and also reveal information about demographics and social and cultural preferences (Emmons \& Mocarski, 2014; Vilnai-Yavetz \& Tifferet, 2015). This is particularly significant when combined, as in Ford's case, with her follower numbers.

Ford's Facebook page expresses multiple elements of her public persona. The cover image promotes Fight Like a Girl, and features a photo of the book, the cover plug from Anne Summers, and an all-caps imperative, inflected for social media, to 'JOIN THE FIGHT. \#FIGHTLIKEAGIRL'. Her Facebook profile links directly to her author page on Daily Life. The content first presented to visitors is a compilation of the photos most recently posted to the page (screenshots of aggressive messages sent to her), and then her most recently posted video (a loop of Leslie Knope from Parks and Recreation, with a caption wishing her

\footnotetext{
${ }^{3}$ Follower statistics and content analysis are based on the pages as at 11 May 2018. Ford's Facebook page can be accessed here: https://www.facebook.com/clementineford/ and her Twitter here: https://twitter.com/clementine ford
} 
followers 'Happy Galentine’s Day'). This content, combining feminism, combative activism, and popular culture, is typical of Ford's social media engagement.

Ford's Facebook page also prominently features a 'pinned post', created 28 January 2016 eight months prior to the book's publication — that explicitly outlines rules for participating in conversation on her page. ${ }^{4}$ These eleven rules of discourse are expressed in a style consistent with Ford's own posts to Facebook, as well as with her writing in Fight Like a Girl. ${ }^{5}$ Although beginning with a welcome, each 'rule' is addressed directly to the people not welcome on Ford's Facebook: the 'you' in many of them is those 'actively opposed to feminism'. The language is performative as well as functional in its expectation setting: it outlines expectations, and directly demonstrates the response that violating these rules will elicit. Ford's Facebook page thus simultaneously presents a particular version of Fordquirky, feminist, and authorised through both media and print publications — while combatively defending the role of the page as creating a space for intersectional feminist content sharing and community dialogue.

Ford's Twitter combines similar brand-building features. Her Twitter banner is a screenshot from the Australian film Muriel's Wedding (1994). Characters Rhonda, Tanya and Nicole, on holiday in Hibiscus Island, wear fruit hats and bikinis and scowl down at the camera. Her Twitter bio, 'Unfuckwithable feminist demogorgon', continues the theme of the antagonistic, glamorous woman, and suggests another tacit popular culture reference, with the demogorgon a key feature of hit sci-fi series Stranger Things (2016). Again, an item is prominently

\footnotetext{
${ }^{4}$ https://www.facebook.com/clementineford/posts/957543664322728

${ }^{5}$ For example: 'This is a space with a very clear political ideology and not everyone has the right to post here or be heard. This especially goes for deliberately obnoxious dickheads who come here purely for the purpose of trolling or disagreeing with every single thing I post because they literally have nothing better to do than demonstrate what a total fucking toolbox they are on Facebook. Get a life, losers. There are thousands of groups catering to racist, sexist, asinine dickblisters that FB refuses to remove, and I'm sure you will be most welcome there with the other missing link specimens who sadly roam this earth. Fuck off and find your people.'
} 
'pinned' to her profile: a Tweet from 28 September 2016 promoting Fight Like a Girl, reading 'I dipped a quill in the inky ocean of male tears and wrote an angry manifesto. You can buy it here! https://t.co/hZWVVkWqfS \#FightLikeAGirl'. ${ }^{6}$ Like Ford's Facebook profile, her Twitter combines strategic popular culture mentions, combative feminism, humour, and the authorising reminders of her print publishing record.

Ford's social media profiles frame her online activities. But what kind of content is she sharing, and what conversation generating, via social media? Over a four-month sample, her Facebook posts fall into three main categories: ${ }^{7}$

1. Response: Conversation about prominent news items relating to gender equality and intersectional feminist politics, broadly defined. This includes both local Australian news and big international stories.

2. Conversation: Reflection on issues relating to gender equality and intersectional feminist politics, broadly defined.

3. Promotion: Sharing of Ford's own journalistic pieces.

4. Signal-boosting: Sharing screenshots of misogynist abuse that Ford has received.

Ford herself attracted sustained mainstream media attention for the first time in 2015 when one of her signal-boosting screenshots led to a man being sacked (see e.g. Bruce-Smith, 2015; Caggiano, 2015; Cheer, 2015; Sparrow, 2015; Wright, 2015). As well as creating public awareness of Ford's social media feminist activities through tabloid and broadsheet media, this event drove discussion about Ford in alternative social media spaces in which Ford is not active, including male-centric Reddit, and niche spaces such as popular

\footnotetext{
${ }^{6}$ https://twitter.com/clementine ford/status/781109273283526656

${ }^{7}$ All Facebook posts, including dates and measures of engagement, were collected using Netlytic, a program which uses the Facebook API to collect posts and top-level comments from public pages. The posts used for this analysis cover the four month period from 22 July 2017-22 November 2017.
} 
motherhood forum Essential Baby. ${ }^{8}$ The widespread reception of this event fed back into social media discourse about Ford outside of her own page via conversations on the media outlets' pages. ${ }^{9}$ It also prompted discussions about the legal issues surrounding social media use, including unfair dismissal, the non-consensual sharing of images online, and has since been used as a case study in academic analysis of these areas (see Pen, 2016; Salter, 2017). This event established the potential for Ford's online feminism to cross over from her own communities into other communicative, social and intellectual spaces. It established her as a hybrid public figure: she had cross-platform traction, and was also both a public commentator and the object of commentary. Her initial and now frequent and ongoing sharing of screenshots of abuse have solidified her public figure as relentless and confident, antagonistic and completely unapologetic: she self-consciously presents as someone who will 'fight like a girl'.

\section{The Book}

Fight Like a Girl self-consciously stages itself as a pre-emptive strike in Ford's online struggles with detractors. An aspect of the book's mediatisation is that not only does it use the language and modes of address of social media to frame its arguments, but also stages its arguments in knowing anticipation that, like Ford's previous public interventions, they will be met with extreme online vitriol. Written with an assumption of its reception being mediated by online hate culture, Fight Like a Girl constantly works to pre-empt critics. For example, Ford accompanies a description of herself as a 'man-hating, separatist feminazi hell-bent on installing a matriarchy and imprisoning men as its slaves' with a footnote saying 'I am required by law to state this is a joke' (2016: 72).

\footnotetext{
${ }^{8}$ See https://www.reddit.com/r/australia/comments/3b6fz1/man shamed for trolling_clementine ford/ and http://www.essentialbaby.com.au/forums/index.php?/topic/1156158-clementine-ford/

${ }^{9}$ https://www.facebook.com/sydneymorningherald/posts/10153528824691264
} 
The book in this way offers itself as a sustained critique of anti-feminist trolling. Referring to her practice of sharing screenshots of abusive online exchanges, Ford writes:

All the hateful slurs, the misogynist attempts to undermine you, the furiously violent descriptions of what they'd like to see done to you ... after a while it all becomes white noise. . . . Part of my tactic in fighting the abuse of women online has always been to signal boost it for the benefit of people who either don't know what it's really like or insist that women lie about how prolific and violent it can be. (2016: 172-6)

The book also offers itself as an already mediatised object. That is, it self-consciously frames itself as a node in a post-digital media network comprising multiple platforms, each with their own affordances, not least the possibilities of more or less instantaneous multi-directional communication. As Ford says, albeit with a certain bravado, this combative media environment offers positive as well as negative possibilities for feminist practice: 'Something I've learned along the way is that exposure to abuse in an already hostile world is a feminist's best friend' (2016: 211).

In these respects the book politicises the personal via its sustained analysis of the impacts of mediatisation on feminist practice; an analysis consistent with feminisms that seek to operate at the nexus of the personal and the political. There remains a question, however, as to how this post-convergent media environment potentially impacts feminist practice more generally. In this respect Fight Like a Girl makes an interesting case study, not least since it is the highest profile feminist book published in Australia recently and by far the best selling, with over 45,000 print copies sold. ${ }^{10}$ As others have pointed out (cf. Yearl3 review, n.d.; Simic, 2016), the writing style of the book itself resembles that of a social media post: the book manifests at the level of its text a convergence between the non-fiction book form and social

\footnotetext{
${ }^{10}$ Data provided by Nielsen Bookscan.
} 
media. This is und oubtedly part of the book's textual strategy. It seeks to offer young women practical strategies for fighting back against misogyny in an accessible, readable form.

Yet it remains difficult to discern the book's connection with the broader political sphere or with feminist history. While the book positions itself within a feminist tradition that harks back to the likes of Summers and Dixson it cites little by way of feminist literature or indeed other feminists. It has remarkably little to say about where contemporary misogynistic discourses come from, even as Ford, in her media appearances, has been highly articulate on such matters. Related to this, the book is highly personal in its approach. While collective experience is always inferred, it offers no rubric for collective feminist organisation beyond a combined assault on toxic online masculinity, likewise largely sidestepping conversationsabout race, queerness, Indigeneity, etc—outside Ford's own experiences central to fourthwave feminism. Lacking historicisation of collective experience or any organisational call, Ford's work runs a real risk of limiting itself to promoting a form of 'girl power plus'. While in some contexts (and largely for white, middle-class subjects) a useful pragmatic strategy, this reduces feminism to the neoliberal politics of the individual actor, decontextualised despite rich histories of feminist critique and organisation. These issues are not specific to Ford's work, and form the basis of broader critiques of the individualised 'solution' to misogyny - that of personal empowerment and increased visibility for certain forms of white, middle-class feminine subjects—offered up by popular feminism (cf. Banet-Weiser, 2018).

Despite these limitations, it is not our intention to underplay Ford's manifest contributions to feminist debate. Rather, we are interested in the book as an artefact and how it represents the moment we are in, and perhaps symptomises the stakes in post-digital feminism. Are these the conditions of possibility for popular feminist books now? As the \#MeToo movement amply demonstrates, among many other possible examples, social media offers considerable resources to feminism. But is the downside of these forms of mediatisation a requirement for 
highly-attenuated self-referentiality that potentially loses any sense of its movement context, occasioned by a constant requirement for pre-emptive strikes and a requirement to be instantly engaging and compelling at cost of historical depth? Or is Fight Like a Girl a canny articulation of the realisation that this, now, is how feminism must necessarily operate, and that to speak to young women about how to deal with toxic masculinity is necessarily to mobilise the politics of the personal and the neoliberal rhetoric of self-governmentality and the 'care of the self', while at the same time laughing off inevitable aggressive attacks?

\section{The Reception}

The reception of Fight Like a Girl, beyond the modest and generally positive journalistic reviews quoted above, consists of intense spikes in conversation on social media, against a backdrop of consistent reviewing on bookish social media such as Goodreads.

In June 2017, Brisbane-based bookshop Avid Reader shared a Facebook post of Ford's, excitedly announcing that Allen \& Unwin had contracted the sequel to Fight Like a Girl (see screenshot, Figure 1, below). Within hours the MRA-inflected trollspace had picked up on the post and Avid Reader's Facebook page was being bombarded with one-star reviews: identity politics were once again under siege online. The scale of the attack indicates that it was organised, most likely in one of the avowedly misogynistic online fora discussed above. The response from bookish and feminist online communities was equally concerted, with a wave of five-star reviews driven by the bookshop's own humorous responses, in combination with signal-boosting from prominent Australian writers connected with Avid Reader such as Ben Law, and further prompted by conversations happening in semi-private feminist bookish spaces, including Facebook groups for women writers. ${ }^{11}$ Within hours the bookshop received

\footnotetext{
${ }^{11}$ For example, Benjamin Law's tweet sharing a screenshot of Avid Reader's funny response to a troll on Facebook garnered 17 replies, 165 retweets and 874 favourites: https://twitter.com/mrbenjaminlaw/status/879256299547971584
} 
more than 2000 five-star reviews in response to the trolling, as well as numerous other shows of support-positive posts, supportive conversation, and even a homemade cake from a regular customer. ${ }^{12}$ At the time of writing, the bookshop has a total of 4,700 reviews, with an average rating of 4.7: 4300 or $91 \%$ of these reviews are five stars; 384 or $8 \%$ are one star.

Tellingly, the bookshop has only received a total of 47 reviews that are not five or one star: exactly $1 \%$ of their overall reviews (see Figure 2 ). ${ }^{13}$

\section{[Insert Figure 1 here]}

\section{[Insert Figure 2 here].}

The scale of the response to this event suggests a strong relationship between bookish communities supportive of Avid Reader and feminist communities supportive of Ford: people like gay, feminist Asian-Australian author Ben Law, who has also worked at Avid Reader in the past, are unsurprisingly at the nexus of this (cf. Law, 2013). It also demonstrates these communities' facility with and activity on social media. Metrics for this activity include the spike in activity on the page, as well as the significant traction garnered by individual posts on this issue. For 26 June and 27 June, there were 137 and 144 posts and comments on the page respectively, in addition to these reviews; the average number for the seven weeks following was 26 (see Figure 3, below). Over the same period, Avid Reader posted 155 times, and their posts averaged 117 likes (see Figure 4, below). Their seven most 'liked' posts are all explicitly linked to this event: the initial post, sharing Ford's news, garnered 608; the

\footnotetext{
${ }^{12}$ See Facebook post from 27 June 2017, 'Thank you so much to our wonderful regular customer Victoria for baking us an ANTI-TROLL SOUR CREAM AND WALNUT CAKE. 0 ': https://www.facebook.com/avidreaderbookshop/posts/10154964018228992

13 These statistics were recorded on 21 June 2018.
} 
other six received between 800 and 2700 . Leaving out these outliers, their posts to the page averaged 54 likes each over this seven-week period. ${ }^{14}$

\section{[Insert Figure 3 here]}

\section{[Insert Figure 4 here]}

We can compare the patterns of reviewing, and of attention, that Avid Reader garnered for supporting Ford with patterns of attention for Fight Like a Girl. The reviews on Amazon in particular reveal the influence of similar communities and events. On Amazon.com, the book has 43 total reviews, with an overall average rating of 3.5 stars. On Amazon.com.au, the book has 64 total reviews, with an overall average rating of 3.7 stars. Both of these are significantly lower than the average rating given to Amazon titles of 4.27 (Dimitrov et al. 2015). Both of these sit slightly below the Goodread s overall rating for the book, which is 3.99 stars. $^{15}$

The Amazon.com and Amazon.com.au reviews spike at one and five stars (see Figure 5, below). This suggests two possibilities. The first is that the book has polarised readers. The second is that, like with the Avid Reader event, a process of trolling and response has occurred. Amazon's 'verified purchases' review function suggests the latter. Figure 6 shows reviews controlled for verified purchases, and demonstrates that people who had actually purchased (and presumably read) the book were proportionally far less likely to give it one-

\footnotetext{
${ }^{14}$ As above, all Facebook posts, including dates and measures of engagement, were collected using Netlytic, a program which uses the Facebook API to collect posts and top-level comments from public pages.

${ }^{15}$ At the time of data collection in June 2018 there were no customer reviews on the British or Canadian Amazon sites; this is expected to soon change, as international publishing rights for the title were bought by OneWorld in December 2017, and the first UK edition published on 2 August 2018.
} 
star reviews than those who had not. The spike in low reviews was not coming from the book's readers, but from other users deliberately targeting its ratings.

\section{[Insert Figure 5 here]}

\section{[Insert Figure 6 here]}

The Goodreads ratings for Fight Like a Girl follow a more predictable, bell-curve-like pattern, with a spike in ratings at 4 stars directly correlating with the mean Goodreads rating for the book, which is 3.99 (see Figure 7, below). This is slightly higher than the average rating given to Goodreads titles, which is 3.88 (Dimitrov et al. 2015). This Goodreads star value is based on 2725 ratings, 389 of which included a review as well. Looking at reviews over time on Goodreads, there is a relatively predictable pattern of initial activity with a slow decrease over time (see Figure 8, below). Spikes in this graph correlate with Christmas giftgiving in 2016 and 2017. Although June 2017 - the Avid Reader moment - in fact represents a trough in Goodreads reviews for the title, 1 star reviews in this month were at their all-time highest; a relatively insignificant total of five (Figure 9).

\section{[Insert Figure 7 here]}

[Insert Figure 8 here]

[Insert Figure 9 here] 
Social media platforms are increasingly central to the production and circulation of cultural products, and to the development of political and cultural communities. The combative nature of many of these political communities drives spikes in social media engagement; contentious content generates more 'likes' and 'comments'. But bookishness can configure social media away from this combativeness, as the Goodreads reception of even a contentious, politicised text like Fight Like a Girl demonstrates. It is relevant, too, to acknowled ge the different demographics that bookishness attracts: as one study of British social media habits showed, Goodreads' users are $69 \%$ female, and women between the ages of 18-34 outnumber men nearly three to one (Statista, 2018). A survey of MRAs on Reddit (N approx. 3000) showed that they were 98\% male, 98\% white, and 87\% 17-20 years old (Zvan, 2014; cf. Duggan \& Smith, 2013, which e.g. shows that overall $15 \%$ of Reddit users are male and 18-29).

\section{Conclusion}

Social media platforms are central to the development of cultural products, communities and political interventions. But these platforms, and these platforms' algorithms, have increasing power over the content that can be shared in these spaces, as well as over who sees what, when, and in what context. The combative nature of the political communities that develop in these also plays a crucial role in positioning feminist texts in what we have called the 'trollspace' of social media interactions. These skirmishes drive spikes in engagement with social media, since contentious content generates more 'likes' and 'comments', and set the tone for subsequent interactions. They frequently lead to the vilification of authors such as Ford and prompt pre-emptive writing strategies that to some degree limit debate and potentially have a censorious impact by discouraging women unprepared to countenance such interactions from participating in debate. 
In the post-digital era, what is the point of a book like Fight Like a Girl? Print books-stillgenerate cultural capital and can act as a springboard for their authors. They also position their authors in a traditional cultural field in a way that social media cannot (yet). Unlike an ephemeral social media post or profile, a book is enduring: a book has both an historical and an archival presence that can itself act as an antid ote to combative social media interactions. As an artefact of the feminist movement in 2016, Fight Like a Girl becomes a discrete node in Australian literary networks, variously feminist and mainstream, historical and contemporary, and print and digital. 


\section{Bibliography}

Andersen, Christian Ulrik, Geoff Cox, and Georgios Papadopolous. 2014. "Postdigital Research - Editorial." A Peer-Reviewed Journal About Post-Digital Research 3 (1). Accessed August 31, 2018. http://www.aprja.net/?page_id=1327.

Andersen, Christian Ulrik, and Søren Bro Pold. 2014. "Post-Digital Books and Disruptive Literary Machines." Formules 18: 169-188. Accessed August 31, 2018. http://www.ieeff.org/f18tocfinal.pdf.

Banet-Weiser, Sarah. 2018. Empowered: Popular Feminism and Popular Misogyny. Durham: Duke University Press. , and Kate Miltner. 2016. "\#MasculinitySoFragile: Culture, Structure, and Networked Misogyny.” Feminist Media Studies 16 (1): 171-4.

Bennett, Laura. 2015. “The First-Person Industrial Complex.” Slate, September 14, 2015. Accessed August 31, 2018. http://www.slate.com/articles/life/technology/2015/09/the_first_person_industrial_complex_ how_the_harrowing_personal_essay_took.html.

Brabon, Katherine. 2016. "Fight Like a Girl Review: Clementine Ford's Snapshot of Contemporary Feminism." Sydney Morning Herald, December 2, 2016.

Bruce-Smith, Alex. 2015. "Man Shamed By Clementine Ford Apologies, Says 'It Was A Bad Joke."” Pedestrian Daily, June 26, 2015. Accessed August 31, 2018.

https://www.ped estrian.tv/news/man-shamed-by-clementine-ford-apologies-says-it-was-abad-joke/.

Caggiano, Anthony. 2015. "Man Shamed for Trolling Clementine Ford Apologises for Online Attack." Sydney Morning Herald, June 25, 2015.

Cheer, Louise. 2015. "Man Who Threatened to Rape and Bash Columnist Apologises for His 'Stupid' Act... and Now Complains HE Is Being Trolled." Daily Mail Australia, June 26, 2015.

Chess, Shira, and Adrienne Shaw. 2015. "A Conspiracy of Fishes, Or, How We Learned to Stop Worrying About\# GamerGate and Embrace Hegemonic Masculinity." Journal of Broadcasting \& Electronic Media 59 (1): 208-20.

Coleman, Gabriella. 2012. "Our Weirdness Is Free: The Logic of Anonymous - Online Army, Agent of Chaos, and Seeker of Justice'." Triple Canopy, 2012. Accessed August 31, 2018. https://www.canopycanopycanopy.com/contents/our_weirdness_is_free.

Crenshaw, Kimberle. 1989. "Demarginalizing the Intersection of Race and Sex: A Black Feminist Critique of Antidiscrimination Doctrine, Feminist Theory and Antiracist Politics." University of Chicago Legal Forum 140: 139-67.

Crispin, Jessa. 2017. Why I Am Not a Feminist: A Feminist Manifesto. Brooklyn: Melville House.

Dahl Crossley, Alison. 2017. Finding Feminism: Millennial Activists and the Unfinished Gender Revolution. New York: New York University Press. 
Davis, Mark. 2016. "The Changing Literary Ecology." In The Return of Print? Contemporary Australian Publishing, edited by Aaron Mannion and Emmett Stinson, 47-65. Melbourne: Monash University Publishing.

. 2017. "Who Are the New Gatekeepers? Literary Mediation and Post-Digital Publishing." In Publishing Means Business: Australian Perspectives, edited by Aaron Mannion, Millicent Weber, and Katherine Day, 129-51. Melbourne: Monash University Publishing.

Deacon, David, and James Stanyer. 2014. "Mediatization: Key Concept or Conceptual Bandwagon?" Media, Culture \& Society 36 (7): 1032-44.

- 2015. “"Mediatization And'or 'Mediatization Of'? A Response to Hepp et Al." Media, Culture \& Society 37 (4): 655-57.

Dean, Jodi. 1996. Solidarity of Strangers: Feminism After Identity Politics. Berkley: University of California Press.

Delaney, Brigid. 2016. "Clementine Ford: 'There's Something Really Toxic with the Way Men Bond in Australia'." The Guardian, September 28, 2016.

Diamond, Elin. 2012. "Identity Politics Then and Now." Theatre Research International 37 (01): 64-67.

Dimitrov, Stefan, Faiyaz Zamal, Andrew Piper, and Derek Ruths. 2015. "Goodreads Versus Amazon: The Effect of Decoupling Book Reviewing And Book Selling." Ninth International AAAI Conference on Web and Social Media. Accessed August 31, 2018.

https://www.aaai.org/ocs/index.php/ICWSM/ICWSM15/paper/view/10557.

Dixson, Miriam. 1976. The Real Matilda: Woman and Identity in Australia, 1788-1975. Ringwood, VIC: Penguin Books.

Duggan, Maeve, and Aaron Smith. 2013. "6\% of Online Adults Are Reddit Users." Pew Research Center. July 3, 2013. Accessed August 31, 2018.

http://www.pewinternet.org/2013/07/03/6-of-online-adults-are-reddit-users/.

Dzodan, Flavia. 2011. "My Feminism Will Be Intersectional Or It Will Be Bullshit!" Tiger Beatdown. October 10, 2011. Accessed August 31, 2018.

http://tigerbeatd own.com/2011/10/10/my-feminism-will-be-intersectional-or-it-will-bebullshit/.

- 2016. "My Feminism Will Be Capitalist, Appropriative and Bullshit Merchandise." Medium. August 9, 2016. Accessed August 31, 2018. https://medium.com/athena-talks/myfeminism-will-be-capitalist-appropriative-and-bullshit-merchandise-d1064490d8fb.

Emmons, Betsy, and Richard Mocarski. 2014. "She Poses, He Performs: A Visual Content Analysis of Male and Female Professional Athlete Facebook Profile Photos." Visual Communication Quarterly 21 (3): 125-37.

Ford, Clementine. 2015. Clementine Ford Tells All About Her Upcoming Debut Book, "Fight Like A Girl" Interview by Pedestrian Daily. Pedestrian Daily. Accessed August 31, 2018. https://www.pedestrian.tv/news/clementine-ford-tells-all-about-her-upcoming-debutbook-fight-like-a-girl/.

2016. Fight Like A Girl. Sydney: Allen \& Unwin. 
Franke, Katherine. 2016. "Making White Supremacy Respectable. Again.” Blog Los Angeles Review of Books. November 21, 2016. Accessed August 31, 2018.

http://blog.lareview of books.org/essays/making-white-supremacy-respectable/.

Freeman, Hadley. 2016. “'Don't Play Identity Politics!' The Primal Scream of the Straight White Male." The Guardian, December 3, 2016.

Gay, Roxane. 2014. Bad Feminist. Lond on: Hachette UK.

Gilley, Jennifer. 2016. "Feminist Publishing/Publishing Feminism: Experimentation in Second-Wave Book Publishing." In This Book Is an Action: Feminist Print Culture and Activist Aesthetics, edited by Jaime Harker and Cecilia Konchar Farr, 23-45. Urbana, IL: University of Illinois Press.

Goldberg, Michelle. 2016. "Democratic Politics Have to Be 'Identity Politics."' Slate, November 2016. Accessed August 31, 2018.

http://www.slate.com/articles/news_and_politics/politics/2016/11/democratic_politics_have_t o_be_identity_politics.html.

Hanisch, Carol. 1970. “The Personal Is Political." In Notes from the Second Year: Women's Liberation: Major Writings of the Radical Feminists, edited by Shulamith Firestone and Anne Koedt. New York: Pamphlet.

Harker, Jaime, and Cecilia Konchar Farr, eds. 2016. This Book Is an Action: Feminist Print Culture and Activist Aesthetics. Urbana, IL: University of Illinois Press.

Heberle, Renee. 2015. “The Personal Is Political.” The Oxford Handbook of Feminist Theory. Oxford: Oxford University Press. Hepp, Andreas, Stig Hjarvard, and Knut Lundby. 2015. "Mediatization: Theorizing the Interplay between Media, Culture and Society." Media, Culture \& Society 37 (2): 314-24.

Hepp, Andreas, Stig Hjarvard, and Knut Lundby. 2015. "Mediatization: Theorizing the Interplay between Media, Culture and Society." Media, Culture \& Society 37 (2): 314-24.

Herring, Susan, Kirk Job-Sluder, Rebecca Scheckler, and Sasha Barab. 2002. "Searching for Safety Online: Managing 'Trolling' in a Feminist Forum.” The Information Society 18 (5): $371-84$.

Jane, Emma. 2014a. “"Back to the Kitchen, Cunt': Speaking the Unspeakable about Online Misogyny.” Continuum 28 (4): 558-70.

- 2014b. "“Your a Ugly, Whorish, Slut' Understanding E-Bile.” Feminist Media Studies 14 (4): 531-46.

—. 2016. “Online Misogyny and Feminist Digilantism." Continuum 30 (3): 284-97.

Law, Benjamin. 2013. "Why Gay Men Should Be Feminists." Daily Life, June 4, 2013. Accessed August 31, 2018. http://www.dailylife.com.au/news-and-views/dl-opinion/whygay-men-should-be-feminists-20130604-2nnhn.html.

Lilla, Mark. 2016. "The End of Identity Liberalism." The New York Times, November 18, 2016.

Ludovico, Alessandro. 2013. Post-Digital Print: The Mutation of Publishing since 1894. Eindhoven: Onomatopee. 
Lunt, Peter, and Sonia Livingstone. 2016. 'Is 'Mediatization' the New Paradigm for Our Field? A Commentary on Deacon and Stanyer $(2014,2015)$ and Hepp, Hjarvard and Lundby (2015)." Media, Culture \& Society 38 (3): 462-70.

Lupton, Christina. 2011. Knowing Books: The Consciousness of Mediation in EighteenthCentury Britain. Philadelphia: University of Pennsylvania Press.

Manivannan, Vyshali. 2013. "Tits or GTFO: The Logics of Misogyny on 4chan's Random /B/." The Fibreculture Journal 22: 109-32.

Marwick, Alice E., and Robyn Caplan. 2018. "Drinking Male Tears: Language, the Manosphere, and Networked Harassment." Feminist Media Studies 18 (4): 543-559.

Mercer, Jan, ed. 1975. The Other Half: Women in Australian Society. Ringwood, VIC: Penguin Books.

Milner, Ryan M. 2013a. "Hacking the Social: Internet Memes, Identity Antagonism, and the Logic of Lulz." The Fibreculture Journal, no. 22: 62-92.

2013b. "Media Lingua Franca: Fixity, Novelty, and Vernacular Creativity in Internet Memes." Selected Papers of Internet Research 3. Accessed August 31, 2018. http://www.academia.edu/d ownload/32200861/Milner-MemesVC.pdf.

Mouffe, Chantal. 2013. Agonistics: Thinking the World Politically. London and New York: Verso.

Munro, Ealasaid. "Feminism: A Fourth Wave?” Political Insight 4, no. 2 (2013): 22-25.

Murray, Padmini Ray, and Claire Squires. 2013. "The Digital Publishing Communications Circuit." Book 2.03 (1): 3-23.

Murray, Simone. 2015. "Charting the Digital Literary Sphere." Contemporary Literature 56 (2): 311-39.

2018. The Digital Literary Sphere. Baltimore: Johns Hopkins University Press.

Pen, Justin. 2016. “'Never Tweet?': Social Media and Unfair Dismissal.” Alternative Law Journal 41 (4): 271-74.

Phillips, Whitney. 2015. This Is Why We Can't Have Nice Things: Mapping the Relationship between Online Trolling and Mainstream Culture. Cambridge, MA: MIT Press.

Salter, Michael. 2017. Crime, Justice and Social Media. London: Routledge.

Salvo, Natalie. 2017. "Book Review: Clementine Ford's Fight Like A Girl Is an Uncompromising and Important Feminist Polemic.” The AU Review, April 19, 2017. Accessed August 31, 2018. http://arts.theaureview.com/reviews/book-review-clementineford s-fight-like-a-girl-is-an-uncompromising-and-important-feminist-polemic/.

Schulz, Winfried. 2004. "Reconstructing Mediatization as an Analytical Concept." European Journal of Communication 19 (1): 87-101.

Scott, Joan. 1992. "Multiculturalism and the Politics of Identity." October 61: 12-19.

Shaw, Frances. 2013. “Still 'Searching for Safety Online': Collective Strategies and Discursive Resistance to Trolling and Harassment in a Feminist Network." The Fibreculture Journal 22: Trolls and The Negative Space of the Internet. Accessed August 31, 2018. 
http://twentytwo.fibreculturejournal.org/fcj-157-still-searching-for-safety-online-collectivestrategies-and-discursive-resistance-to-trolling-and-harassment-in-a-feminist-network/.

Simic, Zora. 2016. "First Person Feminism: Fight Like A Girl by Clementine Ford." Sydney Review of Books, December 12, 2016. Accessed August 31, 2018.

https://sydneyreviewofbooks.com/fight-like-a-girl-clementine-ford-review/.

Sparrow, Jeff. 2015. "The Complex World of 'Social Media Shamings."” ABC News, June 26, 2015. Accessed August 31, 2018. http://www.abc.net.au/news/2015-06-26/sparrow-thecomplex-world-of-social-media-shamings/6576046.

Statista. 2018. "Distribution of the Online Audience of Goodreads.com in Great Britain (GB) in 2018, by Age Group and Gender." Statista. Accessed August 31, 2018.

https://www.statista.com/statistics/490362/gb-online-aud ience-of-goodreads-com-2015-byage-group-and-gender/.

Summers, Anne. 1975. Damned Whores and God's Police: The Colonization of Women in Australia. Ringwood, VIC: Penguin Books.

Sydney Morning Herald. n.d. "Clementine Ford." Sydney Morning Herald. n.d. Accessed August 31, 2018. https://www.smh.com.au/by/clementine-ford-hve62.

Tolentino, Jia. 2017. “The Personal-Essay Boom Is Over.” The New Yorker, May 18, 2017. van Dijck, José. 2013. “'You Have One Identity': Performing the Self on Facebook and LinkedIn." Media, Culture \& Society 35 (2): 199-215.

Van Schilt, Stephanie. 2017. "Clementine Ford's Fight Like a Girl: Call to Arms from Local Warrior." The Australian, February 3, 2017.

Vilnai-Yavetz, Iris, and Sigal Tifferet. 2015. "A Picture Is Worth a Thousand Words: Segmenting Consumers by Facebook Profile Images.” Journal of Interactive Marketing 32 (November): 53-69.

Walters, Suzanna. 2018. "In Defense of Identity Politics." Signs: Journal of Women in Culture and Society 43 (2): 473-88.

Whittier, Nancy. 2017. "Identity Politics, Consciousness-Raising, and Visibility Politics." In The Oxford Handbook of U.S. Women's Social Movement Activism, edited by Holly J. McCammon, Verta Taylor, Jo Reger, and Rachel Einwohner. Oxford: Oxford University Press.

Wright, Jessica. 2015. “'Enough Is Enough': Clementine Ford to Lodge Police Complaint over Trolling." Sydney Morning Herald, June 26, 2015.

Year13. n.d. "Review: Fight Like a Girl | Clementine Ford." Year13. Accessed August 31, 2018. https://year13.com.au/review-fight-like-girl-clementine-ford/.

Zvan, Stephanie. 2014. "But How Do You Know the MRAs Are Atheists?" Almost Diamonds. April 13, 2014. Accessed August 31, 2018. https://theorbit.net/almostdiamond s/2014/04/13/but-how-d o-you-know-the-mras-are-atheists/.

\section{Figures}


A Avid Reader Bookshop shared a photo

26 June 2017 .

Such brilliant news!

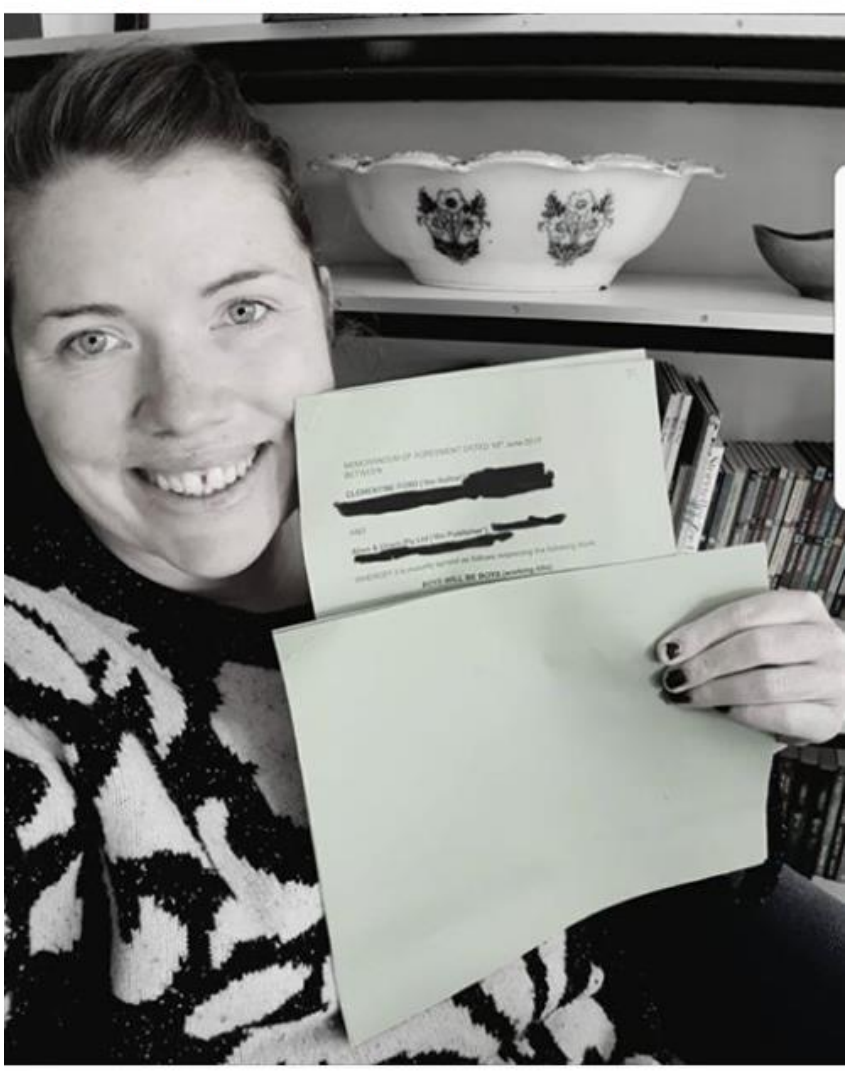

Clementine Ford

25 June $2017 \cdot 0$

Friends, I am absolutely THRILLED to share the news that I have signed a contract with my publisher to write another book. "Boys Will Be Boys" will be published by Allen \& Unwin in late 2018.

Figure 1: Screenshot taken 20 June 2018,

https://www.facebook.com/avidreaderbookshop/posts/10154960714538992 


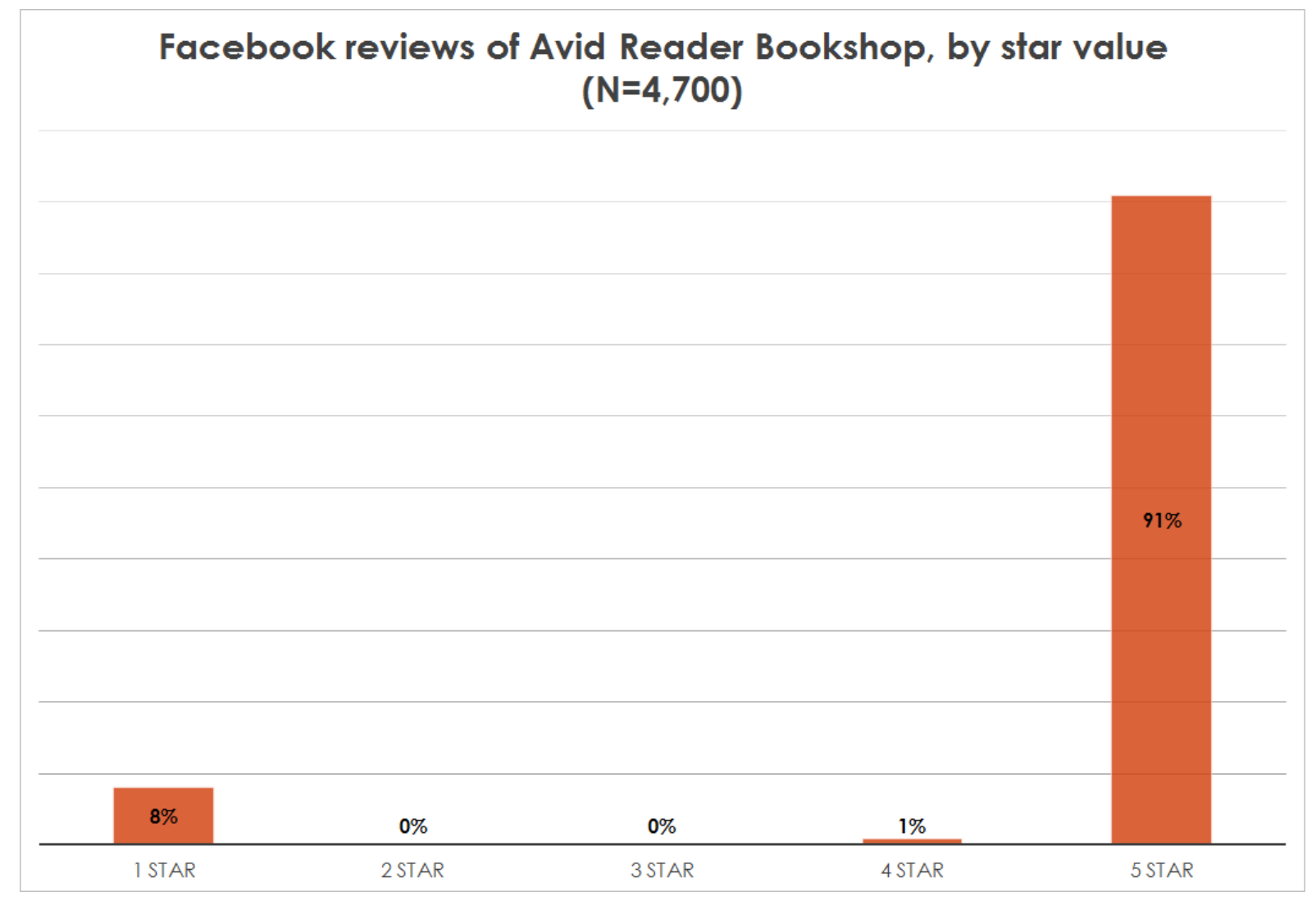

Figure 2: Facebook reviews of Avid Reader Bookshop, by star value 


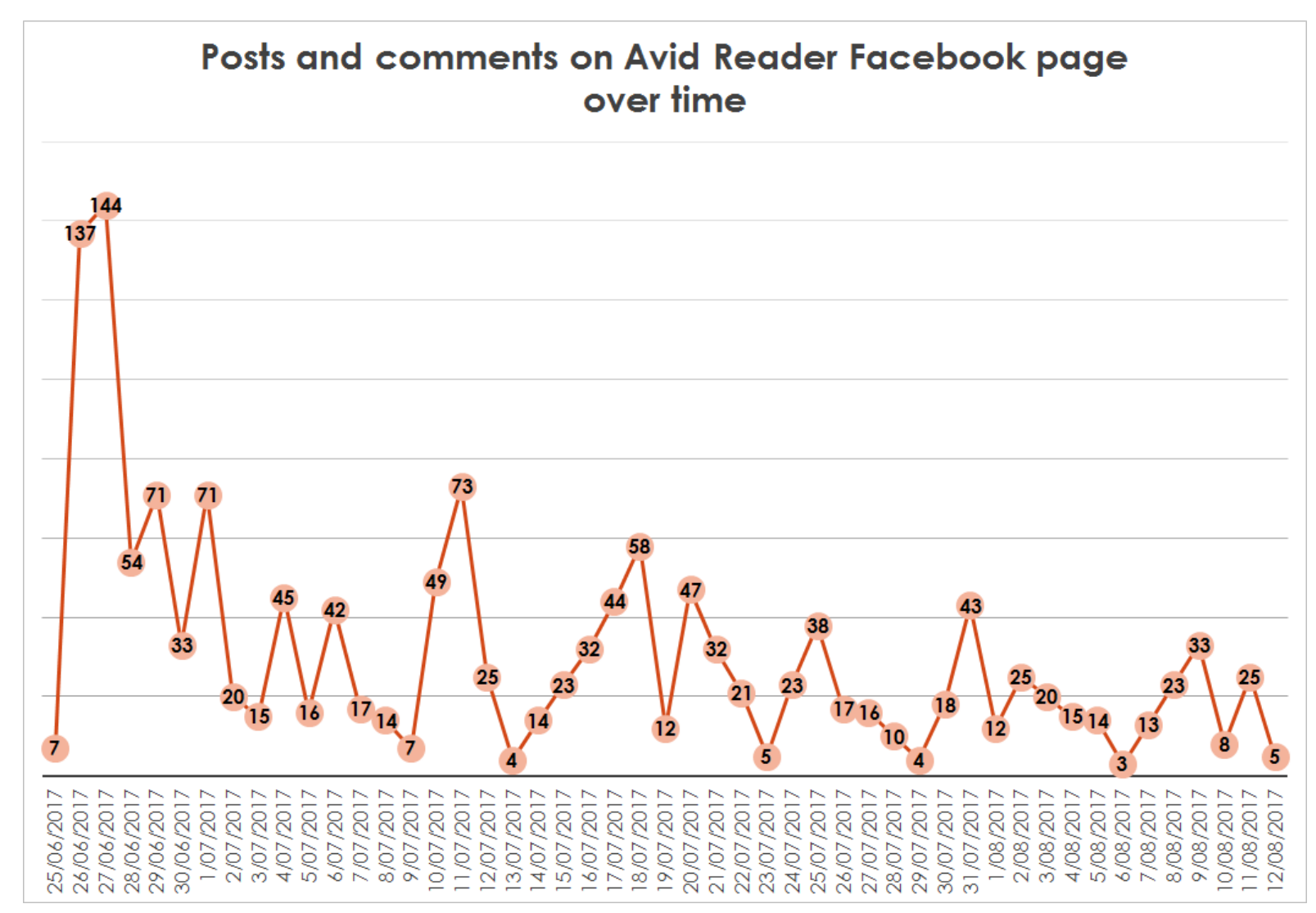

Figure 3: Number of posts and comments on Avid Reader's Facebook page, 25 June 201712 August 2017 
'Likes' of Avid Reader's Facebook posts over time

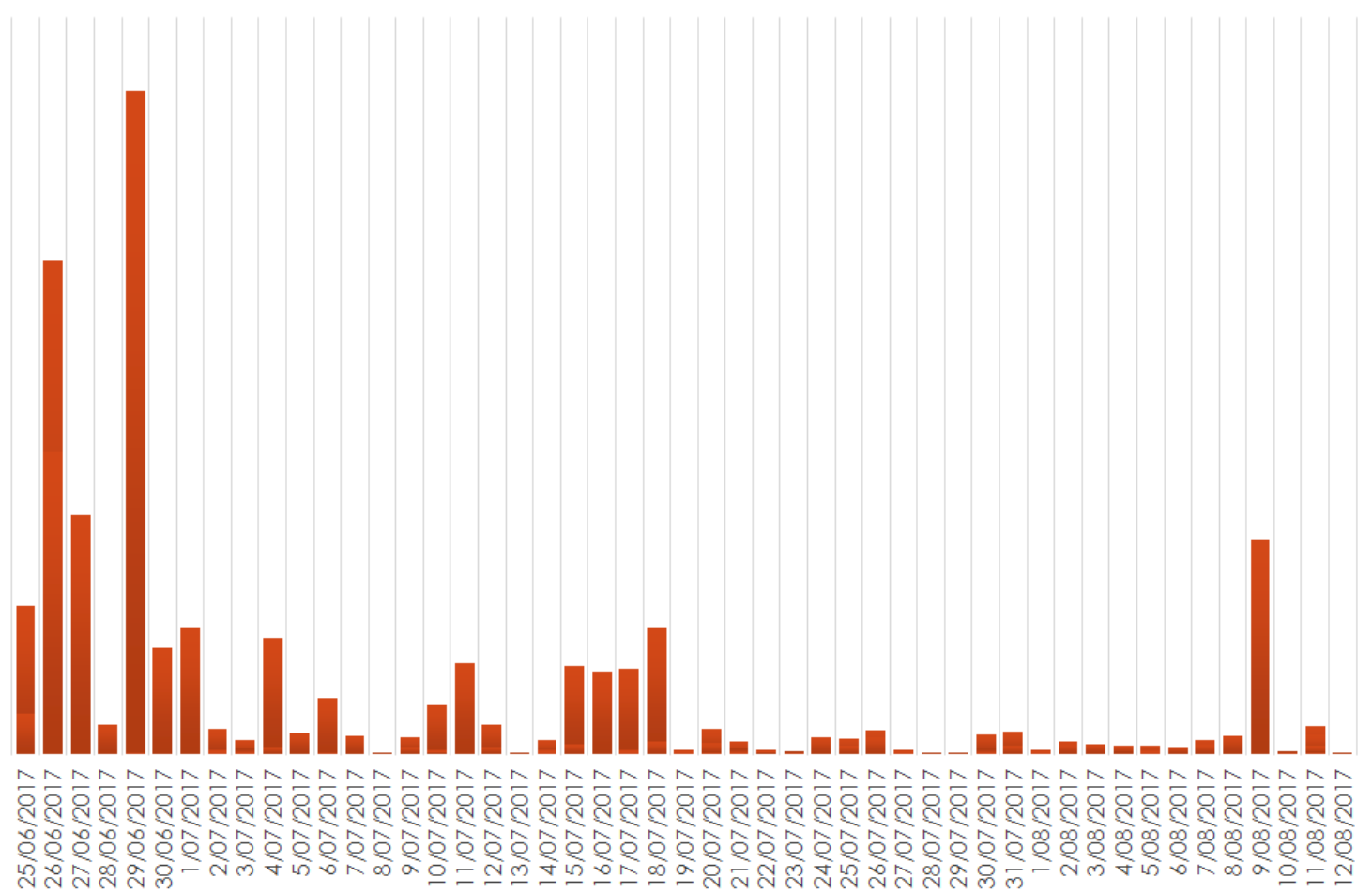

Figure 4: Number of 'likes' of Avid Reader's own Facebook posts, 25 June 2017-12

August 2017 


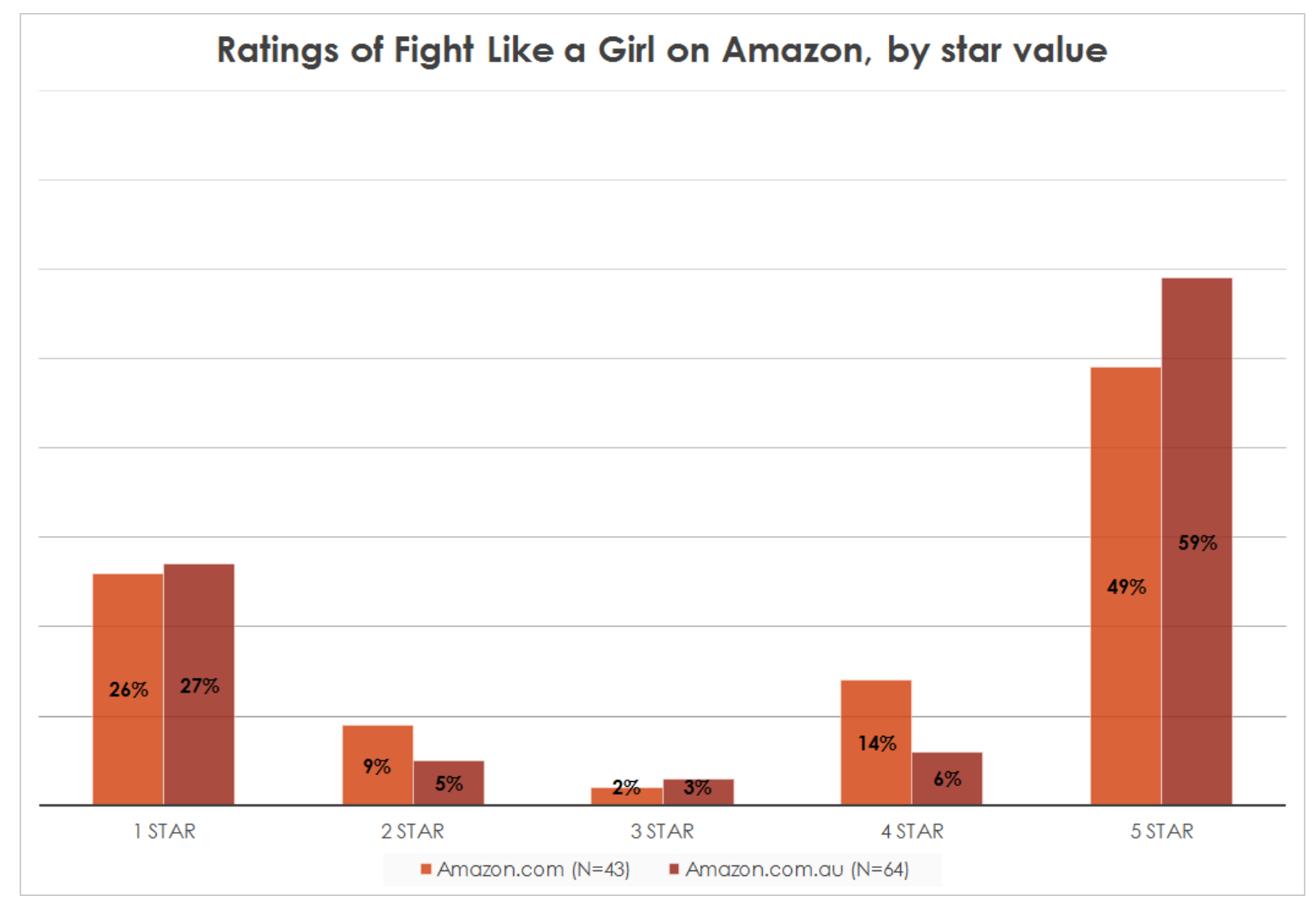

Figure 5: Ratings of Fight Like a Girl on Amazon and Amazon AU 


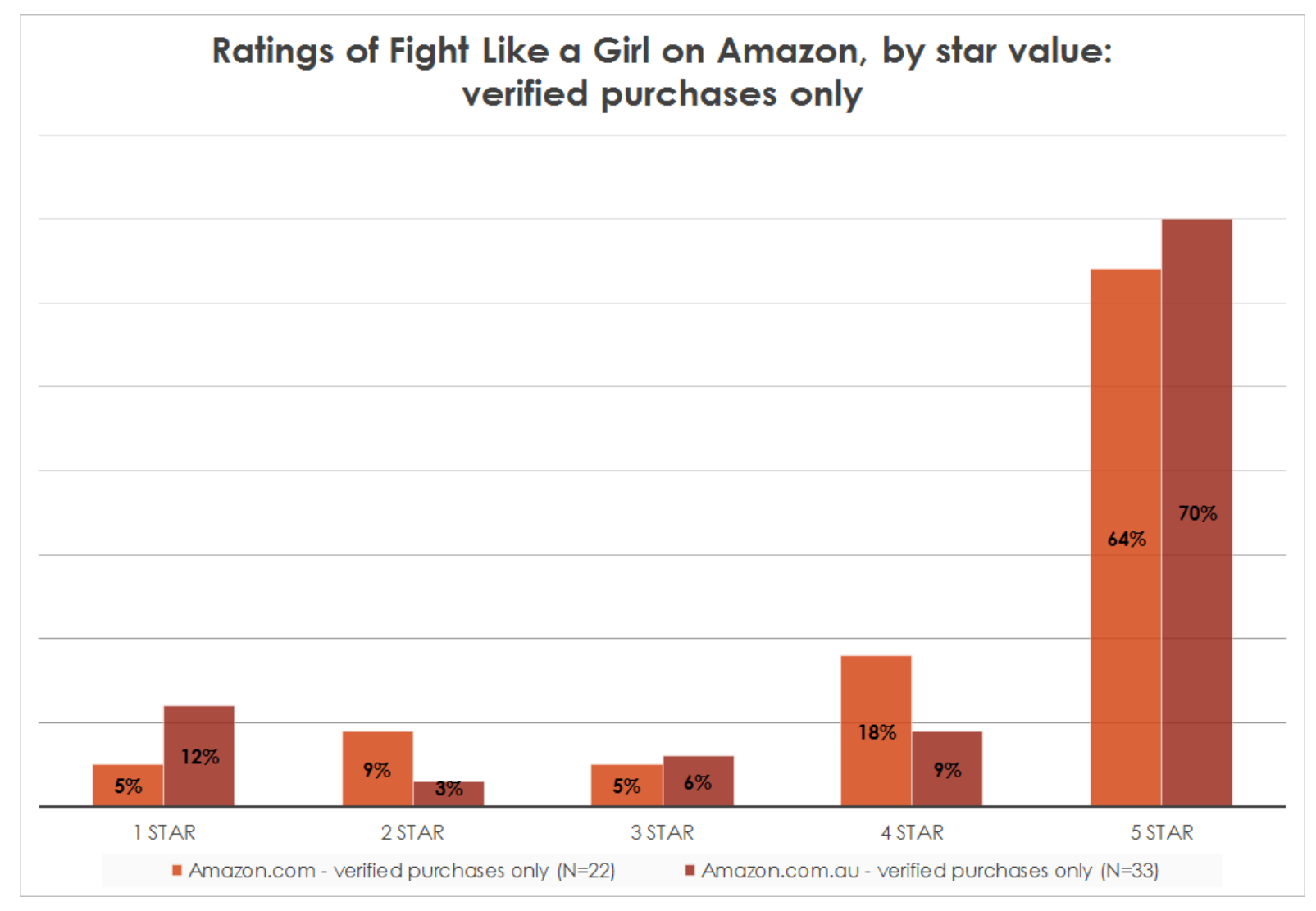

Figure 6: Ratings of Fight Like a Girl on Amazon and Amazon AU; verified purchases only 


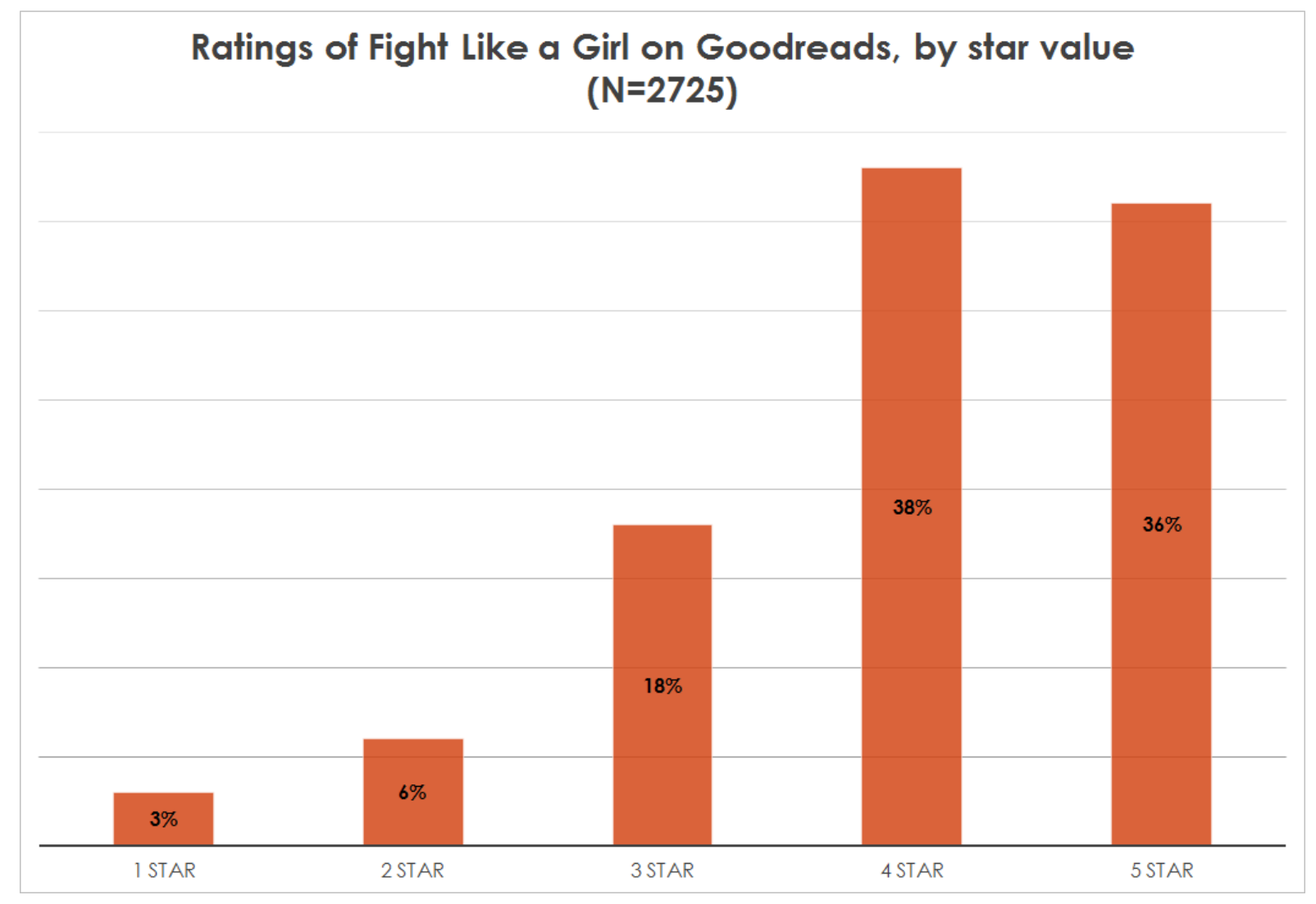

Figure 7: Ratings of Fight Like a Girl on Goodreads 
Goodreads reviews of Fight Like a Girl over time

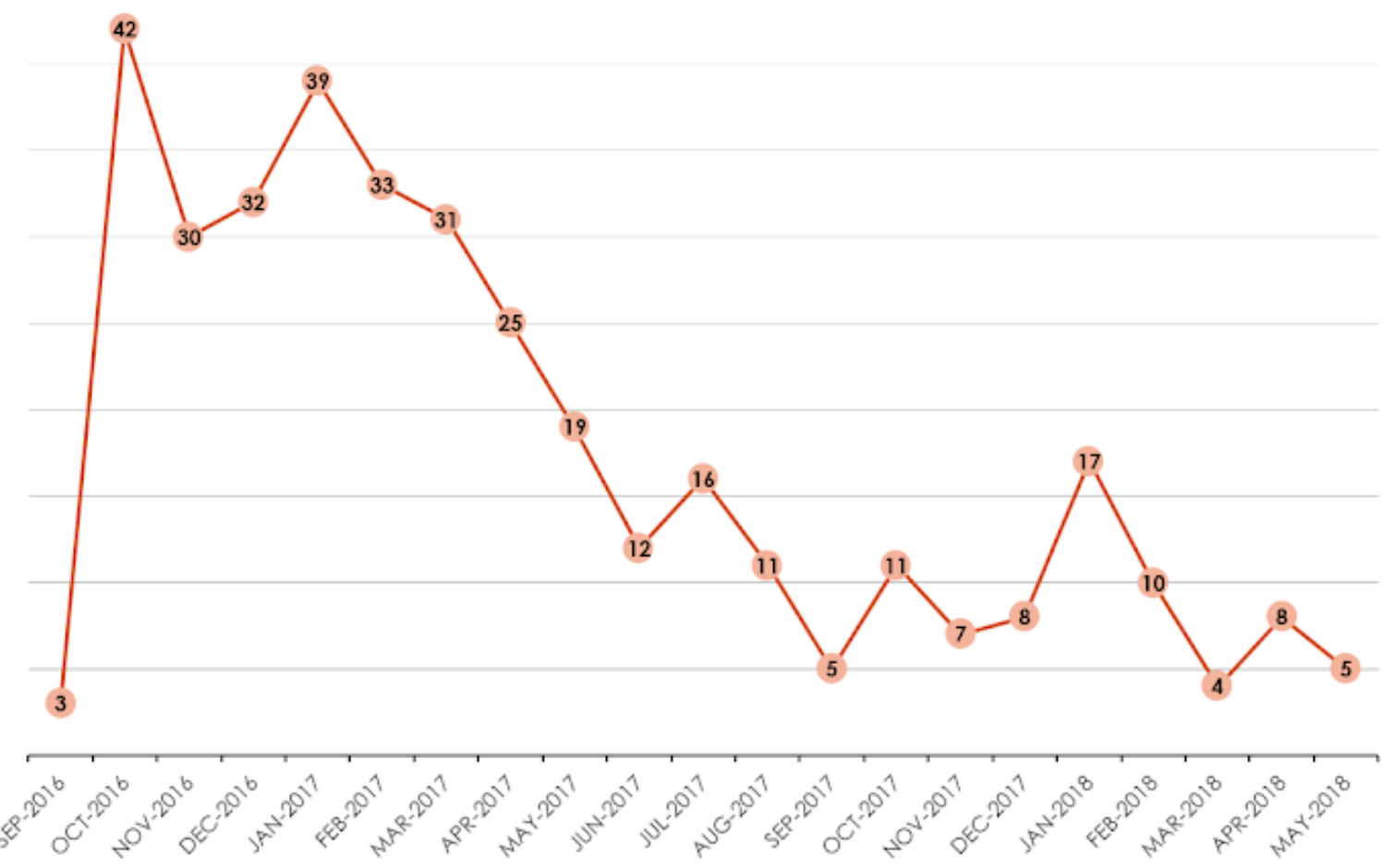

Figure 8: Goodreads reviews of Fight Like a Girl over time 


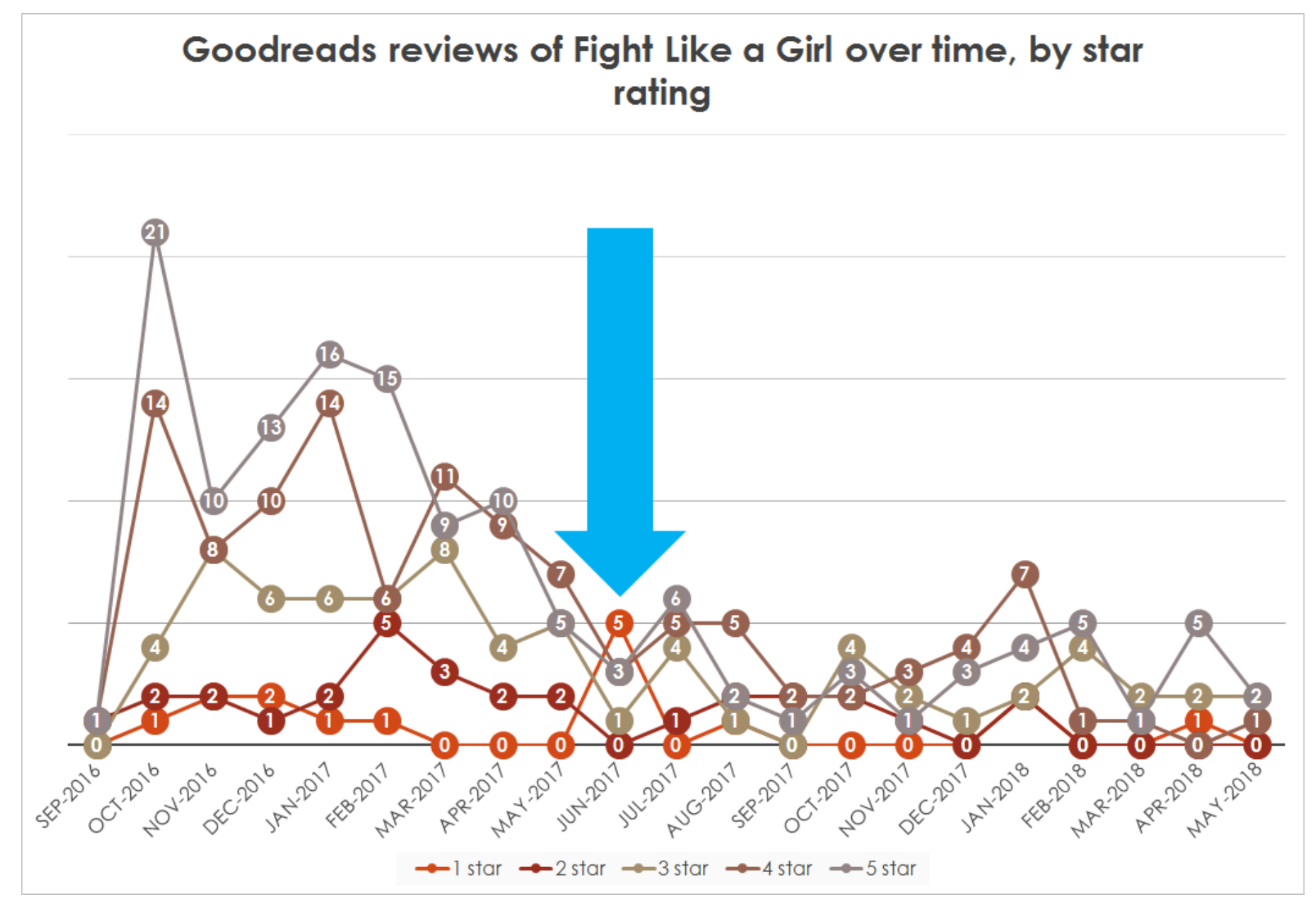

Figure 9: Goodreads reviews of Fight Like a Girl over time, by star rating 